\title{
ESTUDO DA INFLUÊNCIA DE VARIÁVEIS NO PROCESSO DE PRODUÇÃO DE BIOETANOL DE SORO DE LEITE
}

\author{
Fabiane Bach ${ }^{1}$ \\ Mônica Lady Fiorese ${ }^{2}$ \\ Salah Din Mahmud Hasan ${ }^{3}$ \\ Camilo Freddy Mendoza Morejon ${ }^{4}$
}

\begin{abstract}
Resumo: Dentre as matérias-primas mais utilizadas para a produção de etanol, estão os materiais celulósicos, amiláceos, cana de açúcar, açúcar de beterraba e melaço. Fontes alternativas vêm sendo pesquisadas, principalmente as provenientes de resíduos das agroindústrias, sendo um deles o soro de leite. Neste contexto, o objetivo desse trabalho foi estudar a influência das variáveis: temperatura, agitação, concentração de enzima e glicose, durante a produção de bioetanol a partir de soro de leite. A fermentação alcoólica do soro de leite foi realizada seguindo um planejamento experimental fracionário (PEF). A lactose naturalmente presente no soro de leite foi previamente hidrolisada pela enzima lactase. A levedura Saccharomyces cerevisiae foi empregada para realizar a fermentação alcoólica. Os resultados obtidos mostraram que para todas as condições operacionais dos experimentos realizados, houve produção de etanol. Dentre as variáveis analisadas, somente a concentração de glicose adicionada ao meio teve uma influência significativa (estatisticamente $\alpha=0,1$ ), na concentração final de etanol.
\end{abstract}

Palavras-chave: soro de leite, bioetanol, fermentação, resíduo agroindustrial.

\begin{abstract}
Among the most commonly used materials for ethanol production, are cellulosic materials, starch, sugar cane, sugar beet and molasses. Alternative sources have been investigated, especially wastes originated from agro industries, including whey. In this context, the aim of this work was to evaluate the influence of the variables temperature, agitation and enzyme and glucose concentrations during the production of bioethanol from whey. The alcoholic fermentation of whey was carried out following a fractional factorial design (FFD). Lactose naturally present in milk powder was previously hydrolyzed by the enzyme lactase. The yeast Saccharomyces cerevisiae was used in alcoholic fermentation. The results showed that that ethanol was significantly produced in all different operating conditions. Among the variables analyzed, only the glucose concentration added to the medium had a significant influence (statistically $\alpha=0.1$ ), considering the final concentration of ethanol.
\end{abstract}

Keywords: whey, bioethanol, fermentation, agroindustrial residue.

\footnotetext{
${ }^{1}$ Universidade Estadual do Oeste do Paraná - UNIOESTE Campus Toledo - (sc fabi@ hotmail.com)

${ }^{2}$ Universidade Estadual do Oeste do Paraná - UNIOESTE Campus Toledo - (mlfiorese@ gmail.com)

${ }^{3}$ Universidade Estadual do Oeste do Paraná - UNIOESTE Campus Toledo - (salahdmh@ gmail.com)

${ }^{4}$ Universidade Estadual do Oeste do Paraná - UNIOESTE Campus Toledo - (camilo_freddy@ hotmail.com)
} 


\section{INTRODUÇÃO}

O interesse mundial pelo desenvolvimento de biocombustíveis aumentou em virtude de uma preocupação maior com o desenvolvimento de fontes energéticas renováveis e mais limpas. $\mathrm{O}$ bioetanol pode ser obtido a partir de qualquer biomassa que contenha quantidade significativa de amido ou açúcares. O Brasil está pesquisando fontes alternativas para a produção de bioetanol, principalmente as provenientes de resíduos agroindustriais (BNDES; CGEE, 2008).

Vários países estão utilizando o soro de leite, proveniente da produção de queijos, como matéria prima para a produção de etanol. Nos Estados Unidos, Irlanda e particularmente na Nova Zelândia, cerca de $50 \%$ da produção de soro é destinada para esse fim. O soro de leite contém aproximadamente $5 \%$ de lactose, um carboidrato passível de fermentação. Atualmente a levedura Kluyveromyces marxianus é a mais utilizada na fermentação direta. Uma alternativa para a fermentação indireta consiste na hidrólise da lactose pela enzima lactase, liberando os monossacarídeos glicose e galactose, em anaerobiose, estes monossacarídeos são facilmente metabolizados pela levedura $S$. cerevisiae e convertidos em etanol e produtos secundários (Andrade, 2005; Pinheiro, 2004; Hashizume, 2001).

Considerando que $2 \mathrm{~kg}$ de lactose rendam $1 \mathrm{~kg}$ de etanol (Masud, et al 1999), e que a produção de soro de leite sob algum tipo de inspeção, no Brasil em 2010, foi de 6,6 bilhões de litros (Brasil, 2010), a quantidade de soro líquido potencialmente disponível poderia competir com as fontes de matérias primas convencionais para produção de etanol agrícola.

O objetivo desse trabalho foi avaliar a influência das variáveis temperatura, agitação, concentração de enzima e glicose durante a produção de bioetanol de soro de leite in natura.

\section{MATERIAIS E MÉTODOS}

\subsection{CARACTERIZAÇÃO DO SORO DE LEITE}

$\mathrm{O}$ soro de leite in natura desnatado foi cedido pela indústria Sooro Concentrado Indústria de Produtos Lácteos Ltda, situada na cidade de Marechal Cândido Rondon (PR).

Quatro litros $(4,0 \mathrm{~L})$ de soro foram reservados para a realização de análises físico-químicas, o volume excedente foi armazenado no laboratório de Controle de Poluição, do Curso de Engenharia Química da UNIOESTE, Campus de Toledo (PR) sob congelamento a $-23{ }^{\circ} \mathrm{C}$, até ser utilizado na fermentação alcoólica.

Dados sobre o teor máximo residual de gordura no soro após o desnate foram fornecidos pela indústria Sooro Concentrado Indústria de Produtos Lácteos Ltda, sendo o valor informado de $0,1 \%$.

A caracterização do soro de leite in natura desnatado foi realizada por meio das análises em triplicata de acidez Dornic $\left({ }^{\circ} \mathrm{D}\right) \mathrm{e}$ teor de proteína segundo metodologia proposta por Brasil (2006); açúcares redutores (AR), sólidos totais (ST) e cinzas segundo metodologia proposta pelo Instituto Adolfo Lutz (2005); medida de $\mathrm{pH}$ através do equipamento pHmêtro marca MS Tecnopon, modelo MPA210. As análises de DBO, DQO foram realizadas no laboratório de Limnologia Aplicada, do Grupo de Pesquisa em Recursos Pesqueiros e Limnologia (GERPEL) da Unioeste, campus de Toledo/PR.

\subsection{ENZIMA}

A enzima empregada para a hidrólise prévia da lactose presente naturalmente no soro de leite foi LactoMax Flex, cedida pela indústria Prozyn. 


\subsection{MICRO-ORGANISMO}

O micro-organismo utilizado para a realização da fermentação alcoólica do soro de leite foi a levedura comercial $S$. cerevisiae, adquirida na forma de fermento liofilizado da marca Fleishmann.

\subsection{PLANEJAMENTO EXPERIMENTAL}

Um planejamento experimental fracionário (PEF) de resolução IV, com quatro fatores, dois níveis e triplicata no ponto central (Tabela 1), totalizando 11 ensaios (Tabela 2), foi empregado para determinar a influência das variáveis no processo de produção de etanol.

As variáveis analisadas foram: concentrações de enzima e glicose adicionadas ao soro de leite, bem como a temperatura e a agitação do meio fermentescível para um tempo de fermentação alcoólica de 59 horas.

A análise estatística foi realizada por meio do programa computacional STATISTICA (versão 8.0) da StatSoft.
Tabela 1 Variáveis e níveis analisados no planejamento experimental fracionário

\begin{tabular}{cccc}
\hline \multirow{2}{*}{ Variáveis } & \multicolumn{3}{c}{ Nível } \\
\cline { 2 - 4 } & $\mathbf{- 1}$ & $\mathbf{0}$ & $\mathbf{1}$ \\
\hline Lactase $(\%)$ & 0,05 & 0,075 & 0,1 \\
\hline Glicose $\left(\right.$ g. $\left.^{-1}\right)$ & 45 & 55 & 65 \\
\hline Temperatura $\left({ }^{\mathbf{0}} \mathbf{C}\right)$ & 28 & 32 & 36 \\
\hline Agitação $(\mathbf{r p m})$ & 0 & 50 & 100 \\
\hline
\end{tabular}

\subsubsection{Fermentação controle}

A partir dos resultados do PEF, foram realizada três fermentações-controle nas condições ótimas de operação: a primeira (A) contendo o soro de leite in natura, levedura $S$. cerevisiae e enzima lactase, porém sem adição de glicose; a segunda (B) foi realizada em solução aquosa de glicose $\left(65,0\right.$ g.L $\left.{ }^{-1}\right)$, pela levedura $S$. cerevisiae, sem presença de soro de leite in natura e sem adição de enzima lactase. A terceira (C) consistiu na utilização do soro de leite in natura, acrescido de glicose $\left(65 \mathrm{~g} . \mathrm{L}^{-1}\right)$ e enzima lactase, que foi fermentado pela levedura $S$. cerevisiae.

Tabela 2 Experimentos e seus respectivos níveis e fatores

\begin{tabular}{ccccc}
\hline \multirow{2}{*}{ Experimentos } & \multicolumn{5}{c}{ Variáveis } \\
\cline { 2 - 5 } & Temperatura & Agitação & $\begin{array}{c}\text { Concentração } \\
\text { de enzima }\end{array}$ & $\begin{array}{c}\text { Concentração de } \\
\text { glicose }\end{array}$ \\
\hline $\mathbf{1}$ & - & - & - & - \\
\hline $\mathbf{2}$ & + & - & - & + \\
\hline $\mathbf{3}$ & - & + & - & + \\
\hline $\mathbf{5}$ & + & + & + & + \\
\hline $\mathbf{6}$ & - & - & + & - \\
\hline $\mathbf{7}$ & + & - & + & + \\
\hline $\mathbf{8}$ & - & + & + & 0 \\
\hline $\mathbf{9}$ & + & + & 0 & 0 \\
\hline $\mathbf{1 0}$ & 0 & 0 & 0 & - \\
\hline
\end{tabular}




\subsection{FERMENTAÇÃO ALCOÓLICA}

\subsubsection{Preparo do Inóculo}

O inóculo foi preparado separadamente para cada um dos ensaios, com 5,6 \% do volume final de soro de leite a ser fermentado. A metodologia seguida foi proposta por Corazza, et al (2001), e adaptado para a fermentação do soro de leite in natura, em volume igual a 1,0 L, como demonstrado esquematicamente na Figura 1.

Os onze inóculos foram mantidos por 12 horas sob as mesmas condições de temperatura e agitação estabelecidas no PEF para posteriormente serem adicionados ao soro de leite a ser fermentado alcoolicamente.

\subsubsection{Fermentadores}

Frascos de vidro esterilizados, com volume útil de 3,0 L foram adaptados para a realização da fermentação alcoólica. Os mesmos foram hermeticamente fechados, sendo que as coletas de amostras foram realizadas por sucção com seringa, via mangueira. Esta se encontrava permanentemente imersa em solução de água clorada, não havendo a necessidade de abertura dos frascos, impedindo desta forma a contaminação microbiológica do meio.

\subsubsection{Processo Fermentativo}

Os fermentadores, contendo $94,4 \%$ do volume total de soro de leite a ser fermentado, passaram por um processo de hidrólise enzimática para propiciar a quebra da lactose em glicose + galactose açúcares estes assimiláveis pelo microorganismos utilizado neste estudo. Os mesmos foram mantidos a temperatura e agitação determinadas pelo PEF.

Após 6 horas de contato enzima-soro de leite, cada fermentador foi acrescido de glicose PA., conforme PEF. Em seguida adicionou-se o inóculo correspondente. $\mathrm{O}$ mosto permaneceu em fermentação alcoólica por um período de 59 horas.

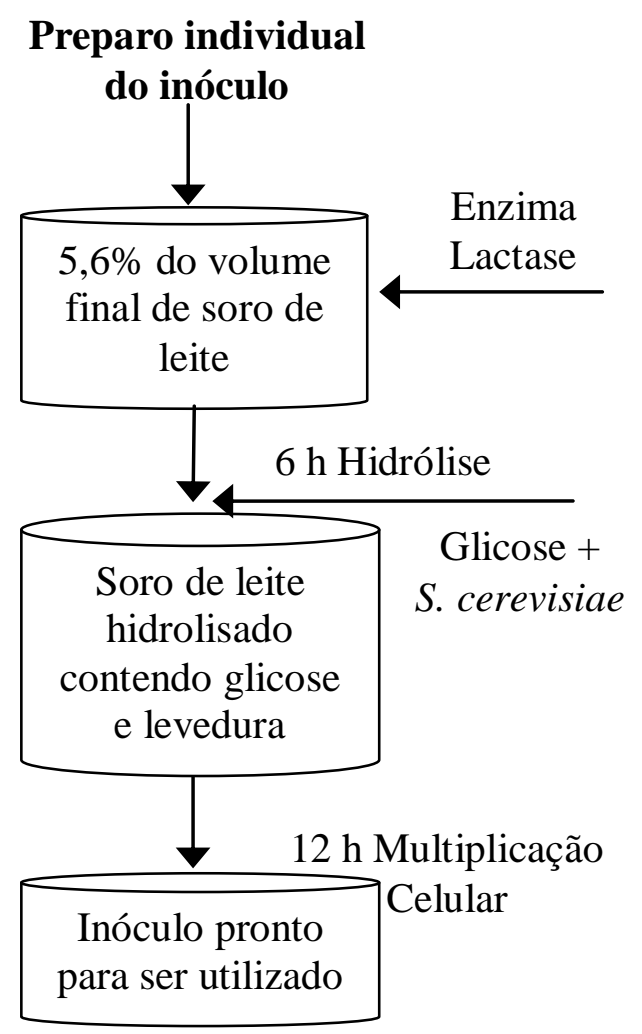

Figura 1 Fluxograma representativo das etapas de preparo do inóculo.

\subsubsection{Monitoramento Fermentação Alcoólica}

Durante a fermentação alcoólica foram realizadas análises, em triplicata, para a verificação do $\mathrm{pH}$, acidez ${ }^{\circ} \mathrm{D}$ e $A R$ conforme metodologias propostas no item 2.1, objetivando delinear o perfil de consumo de $\mathrm{AR}$, alteração de $\mathrm{pH}$ e acidez ${ }^{\circ} \mathrm{D}$ do meio fermentescível. 
As análises foram realizadas nos tempos $0,3,6,9,12,15,23,29,35,47 \mathrm{e}$ 59 horas de fermentação.

Após o término da fermentação alcoólica, os fermentados foram filtrados em papel qualitativo e armazenados em garrafas de vidro de cor âmbar, hermeticamente fechados, até a realização da caracterização físico-química dos mesmos.

\subsection{CARACTERIZAÇÃO FERMENTADO ALCOÓLICO}

DO

A caracterização do fermentado alcoólico produzido foi realizada por meio das análises, em triplicata, de $\mathrm{pH}$; acidez ${ }^{\circ} \mathrm{D}$ e teor de proteína; AR, ST, cinzas, DBO e DQO, conforme metodologias apresentadas no item 2.1. O etanol foi quantificado utilizando um cromatógrafo gasoso, marca Construmaq, modelo U-13. A coluna de separação empregada foi a Carbowax. O gás de arraste utilizado foi o hidrogênio a uma vazão de $60 \mathrm{~mL} \cdot \mathrm{min}^{-1}$. As condições térmicas foram: temperatura da coluna $150{ }^{\circ} \mathrm{C}$; do vaporizador à 131 ${ }^{\circ} \mathrm{C}$; e do detector à $204^{\circ} \mathrm{C}$.

A Figura 2 apresenta o esquema completo do processo fermentativo alcoólico do soro de leite.

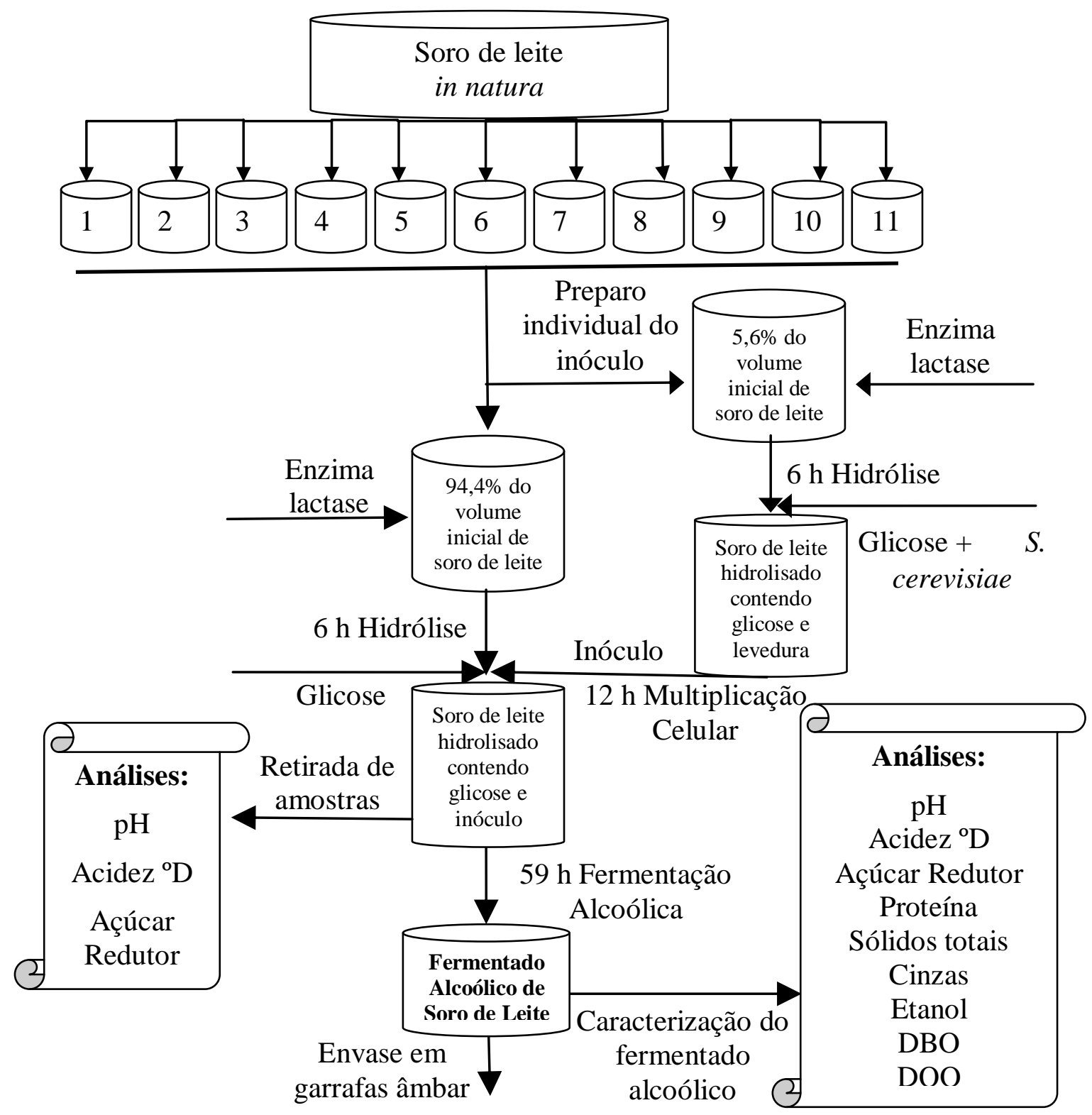

ENGEVISTA, V. 16, n. 3, p.392-409, Setembro 2014 
Figura 2 Fluxograma completo correspondente ao processo fermentativo alcoólico.

\section{RESULTADOS E DISCUSSÃO}

\subsection{CARACTERIZAÇÃO DO SORO DE LEITE}

O soro de leite in natura cedido pela indústria Sooro Concentrado Indústria de Produtos Lácteos Ltda por ser proveniente da mistura de soros doces de diversos laticínios da região, os quais produzem queijos de vários tipos apresentou características diferenciadas.
As análises de caracterização inicial do soro de leite in natura desnatado foram realizadas em triplicata. A média aritmética dos resultados é apresentada na segunda coluna da Tabela 3. As colunas subsequentes são resultados de outros autores.

Comparando as características do soro de leite utilizado na pesquisa com os demais resultados encontrados na literatura, percebe-se a existência de valores semelhantes.

Tabela 3 Caracterização do soro de leite in natura desnatado e comparação com dados de outros pesquisadores

\begin{tabular}{|c|c|c|c|c|c|}
\hline \multirow[b]{2}{*}{ Análise } & $\begin{array}{l}\text { aracterização do } \\
\text { Soro de Leite }\end{array}$ & \multirow{2}{*}{$\begin{array}{l}\text { Pelegrine; } \\
\text { Carrasqueira } \\
\quad(\mathbf{2 0 0 8})\end{array}$} & \multicolumn{2}{|c|}{ Fornari (2006) } & \multirow{2}{*}{$\begin{array}{c}\text { Cunha } \\
\text { et al } \\
(2009)\end{array}$} \\
\hline & $\begin{array}{l}\text { Soro de Leite } \\
\text { Pesnatado In } \\
\text { Natura }\end{array}$ & & $\begin{array}{c}\text { Soro de } \\
\text { Queijo } \\
\text { Mussarela }\end{array}$ & $\begin{array}{c}\text { Soro de } \\
\text { Queijo } \\
\text { Prato }\end{array}$ & \\
\hline pH & 6,30 & - & 6,25 & 6,44 & - \\
\hline $\operatorname{Acidez}^{\circ} \mathrm{D}$ & 9,44 & - & 20 & 15 & - \\
\hline AR\% & 4,76 & - & 4,27 & 3,67 & 4,74 \\
\hline Proteína \% & 0,83 & 0,68 & 0,83 & 0,86 & 0,66 \\
\hline Gordura \% & $<0,1 *$ & 0,44 & 0,74 & 0,77 & 0,16 \\
\hline ST \% & 6,06 & 7,99 & - & - & 6,1 \\
\hline Cinzas \% & 0,55 & 0,5 & - & - & 0,53 \\
\hline DBO (mg.L $\left.L^{-1}\right)$ & 56.734 & - & - & - & - \\
\hline DQO (mg.L L $\left.^{-1}\right)$ & 77.586 & - & - & - & - \\
\hline
\end{tabular}

*Percentual máximo de gordura residual no soro de leite desnatado pela empresa Sooro.

A. R.: Açúcar Redutor.

S. T.: Sólidos Totais.

Os dois constituintes com perceptível diferença, quando comparado com os resultados dos demais autores, foram o percentual de gordura e acidez ${ }^{\circ} \mathrm{D}$. O percentual de gordura ficou abaixo devido a que o soro de leite utilizado na pesquisa já tinha passado por um processo de desnate na indústria que o cedeu.

A acidez ${ }^{\circ} \mathrm{D}$ ficou um pouco abaixo dos encontrados em outras pesquisas $\left(9,44^{\circ} \mathrm{D}\right)$ como, por exemplo, a de Fornari (2006), que obteve $11^{\circ} \mathrm{D}$ e a de Teixeira e Fonseca (2008) que obtiveram acidez igual a $12,49{ }^{\circ} \mathrm{D}$, para soro de leite tipo minas padrão. Esta diferença pode ser consequência da miscelânea de soros que compõem a amostra analisada, do menor percentual de gordura neste soro, que pode apresentar acidez graxa elevada ou ainda da presença de substâncias com característica básica no soro analisado (cloreto de cálcio, hidróxido de sódio). 
Quanto aos valores médios de DBO e DQO do soro de leite utilizado nessa pesquisa, $56.734 \mathrm{mg} . \mathrm{L}^{-1}$ e $77.586 \mathrm{mg} . \mathrm{L}^{-1}$ respectivamente, constata-se que esses se encontram no intervalo de valores citados na literatura que é de 30.000 a 60.000 mg. $\mathrm{L}^{-1}$ de DBO e DQO em torno de $50.000 \mathrm{mg} . \mathrm{L}^{-1}$ (Baldasso, 2008; Andrade, 2005; Alves, 2005).

\subsection{FERMENTAÇÃO ALCOÓLICA}

Durante o processo fermentativo alcoólico, foram acompanhadas características do mosto fermentescível, como a variação de $\mathrm{pH}$, acidez ${ }^{\circ} \mathrm{D}$ e concentração de AR. A fermentação alcoólica foi realizada por um tempo total de $59 \mathrm{~h}$, sendo monitorada ao longo desse período. O comportamento do consumo de
AR pela levedura $S$. cerevisiae em todas as condições testadas é apresentado na Figura 3.

O tempo zero indicado na Figura 3 apresenta a quantidade total de açúcares redutores após a adição de glicose PA aos ensaios, adição esta realizada de acordo com o proposto no PEF, cabe lembrar que o soro de leite in natura apresenta $4,76 \%$ de AR. A diferença obtida de concentração inicial de AR no ponto zero deve-se as diferentes concentrações determinadas no PEF (Tabela 2).

Na Figura 3 é possível visualizar que no decorrer das $59 \mathrm{~h}$ de fermentação ocorre uma redução contínua dos AR, evidenciando que os mesmos devem ter sido consumidos pela $S$. cerevisiae, transformando-os em produto principal (etanol) e produtos secundários.

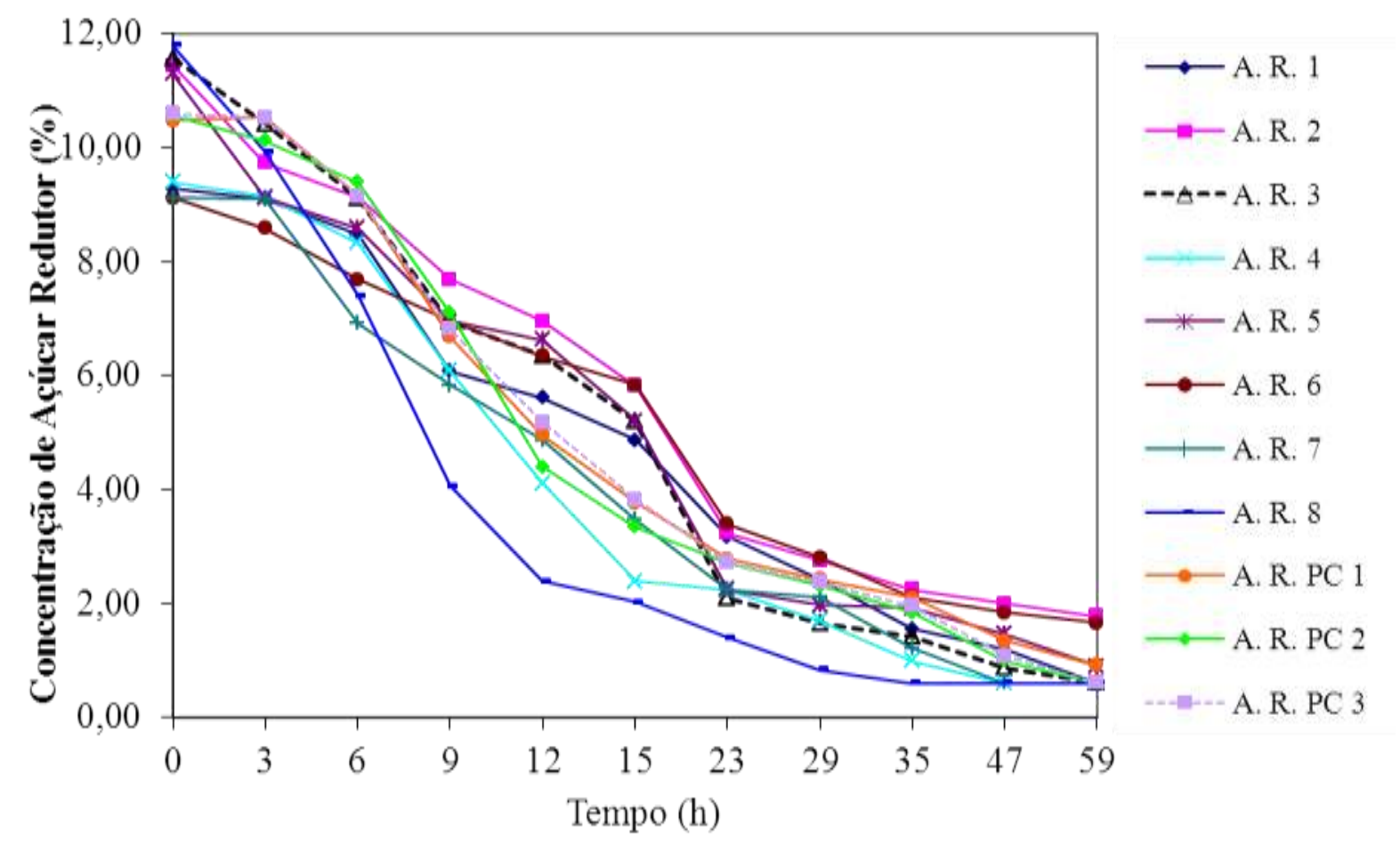

Figura 3 Concentração de açúcar redutor durante a fermentação alcoólica para as todas as condições propostas no PEF.

O mesmo comportamento foi obtido por Kargi e Ozmihci (2005) em seus estudos de fermentação alcoólica de soro de leite reconstituído empregando a levedura Kluyveromyces marxianus e por Christensen et al (2010) realizando fermentação de soro de leite in natura ENGEVISTA, V. 16, n. 3, p.392-409, Setembro 2014 com a levedura $K$. marxianus para produzir etanol.

Observa-se, na Figura 3, uma variação no tempo de consumo dos AR dos onze meios fermentescíveis. A maior diferença é percebida entre os ensaios II e VIII, 
onde o ensaio II demorou aproximadamente $35 \mathrm{~h}$ para reduzir à $2,0 \%$ a concentração de $\mathrm{AR}$ presentes no meio, enquanto o ensaio VIII alcançou esta mesma concentração em apenas $15 \mathrm{~h}$ de fermentação. Como ambos os ensaios foram elaborados com a adição da mesma concentração inicial de glicose, uma possível explicação para a existência dessa diferença pode ser a utilização de inóculos diferentes para cada ensaio. Assim, cada fermentador pode ter recebido um número distinto de células ativas de leveduras fermentativas, sendo que o ensaio que recebeu uma quantidade maior dessas células apresentou uma redução mais rápida dos $\mathrm{AR}$ presentes no meio, isto devido ao maior consumo dos mesmos pelas leveduras presentes em maior quantidade.

O consumo e transformação dos AR, pela levedura, ocasionou a alteração do $\mathrm{pH}$ e acidez ${ }^{\circ} \mathrm{D}$ do meio fermentativo. O comportamento obtido durante a fermentação alcoólica para o valor de $\mathrm{pH}$ e acidez ${ }^{\circ} \mathrm{D}$, dos onze ensaios, encontra-se apresentado nas Figuras 4 e 5, respectivamente. $\mathrm{O} \mathrm{pH}$ do soro de leite in natura desnatado apresentava valor igual a 6,30. Após a adição e homogeneização do inóculo no meio a ser fermentado, o $\mathrm{pH}$ de todos os ensaios apresentaram redução, encontrando-se no intervalo de 4,56 e 6,00. Esses valores são correspondentes ao tempo zero da Figura 4.

A redução do $\mathrm{pH}$ do meio a ser fermentado, após a adição do inóculo, deve-se aos produtos secundários (ácido lático, cítrico e succínico), produzidos no inóculo durante o crescimento celular e multiplicação das leveduras, conforme menciona Hashizume (2001) em seus estudos.

Na Figura 4 observa-se que durante o processo fermentativo alcoólico, todos os ensaios apresentaram comportamentos semelhantes para os valores de $\mathrm{pH}$, verificando-se a redução contínua do mesmo até o tempo aproximado de $15 \mathrm{~h}$ de fermentação e posterior estabilização do mesmo para os ensaios III e VII. Os demais ensaios apresentaram redução do
pH até o final das 59 h de fermentação, porém com menor intensidade devido ao término da fase exponencial que tem duração de aproximadamente $24 \mathrm{~h}$.

Os ensaios I, III, V e VII apresentaram os valores de $\mathrm{pH}$ mais elevados ao final da fermentação alcoólica. A causa pode ter sido a menor concentração de glicose adicionada ao soro de leite, e dessa maneira os produtos secundários formados durante a fermentação alcoólica e responsáveis pela redução do $\mathrm{pH}$ foram produzidos em menor quantidade, resultando em um $\mathrm{pH}$ menos ácido. A diferença de $\mathrm{pH}$ dos meios também está relacionada às condições de temperatura que os mesmos foram submetidos. É possível constatar, observando o PEF (Tabela 2) e a Figura 4, que os inóculos e ensaios submetidos à temperatura de 36 ${ }^{\circ} \mathrm{C}$ (nível +1) apresentaram maior redução de $\mathrm{pH}$. Oliveira (1988) citado por Souza (2009) afirma que para a levedura $S$. cerevisiae temperaturas elevadas afetam o metabolismo da mesma, levando a uma diminuição da tolerância ao etanol e formação de produtos secundários.

Após 59 h de fermentação, o pH dos onze ensaios encontravam-se entre 3,28 4,63. Conforme Figura 4, observa-se que o $\mathrm{pH}$ do Ensaio VI apresentou-se mais ácido do que os demais ensaios, tanto no início da fermentação alcoólica, quanto ao final dela. O Ensaio VI foi submetido à maior temperatura $\left(36{ }^{\circ} \mathrm{C}\right)$, não sofreu agitação, foi acrescido da maior quantidade de lactase $(0,1 \%)$ e da menor concentração de glicose $\left(45,0\right.$ g. $\left.\mathrm{L}^{-1}\right) . \mathrm{O}$ pH mais elevado dentre os ensaios, tanto no início, quanto no final do processo fermentativo alcoólico, foi verificado no Ensaio VII. Este ocorrido numa menor temperatura $\left(28{ }^{\circ} \mathrm{C}\right)$, máxima agitação (100 rpm), máxima concentração de lactase $(0,1 \%)$ e mínima concentração de glicose $\left(45,0\right.$ g.L $\left.\mathrm{L}^{-1}\right)$.

Após a fermentação do soro de leite para a produção de aguardente, Suzart (2007) verificou que o fermentado alcoólico produzido em seus experimentos apresentava-se com pH igual a 4,02. Este valor encontra-se dentro do intervalo de valores de $\mathrm{pH}$ verificados nos onze 
fermentados alcoólicos de soro de leite desta pesquisa.

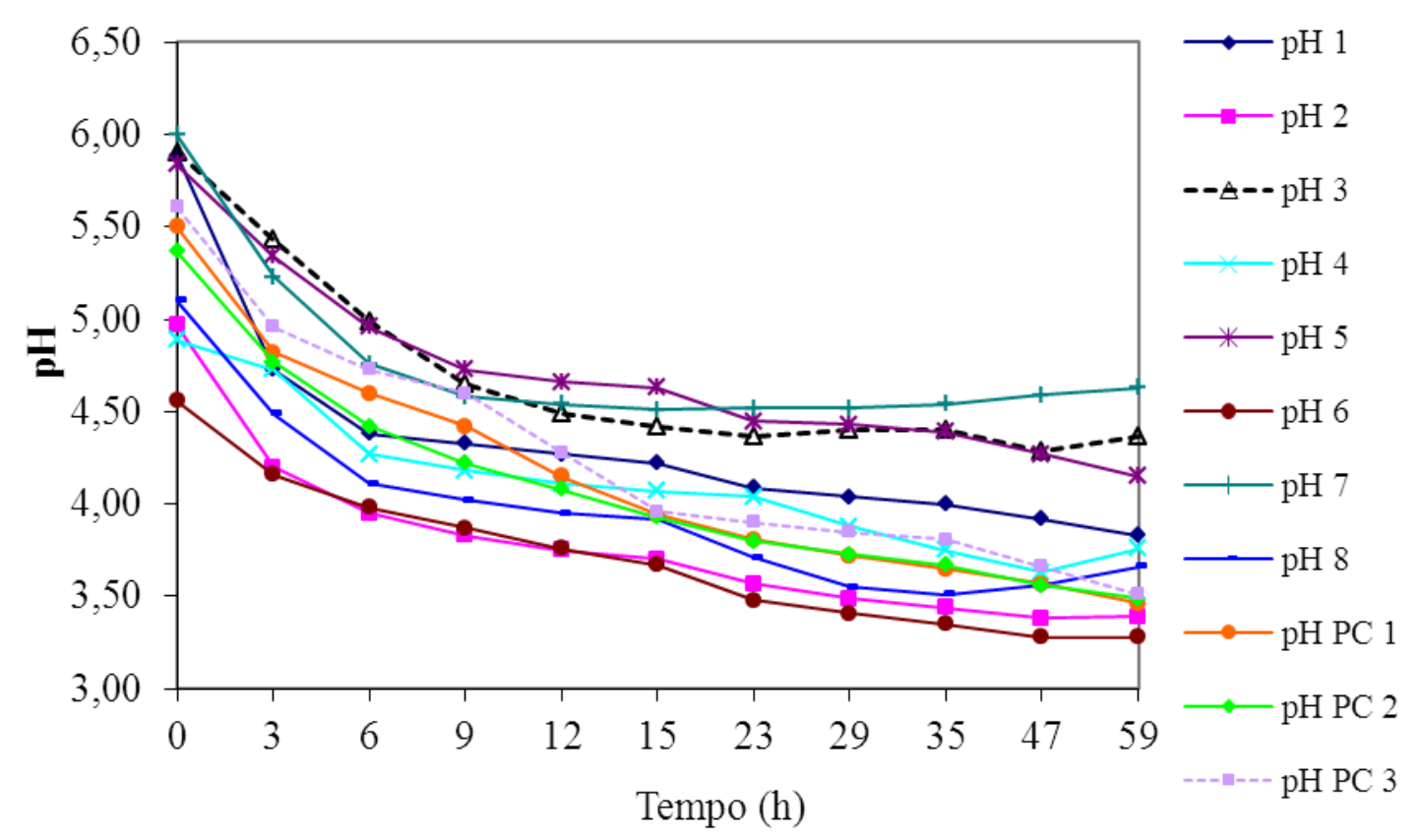

Figura 4 Comportamento do pH do meio fermentativo alcoólico.

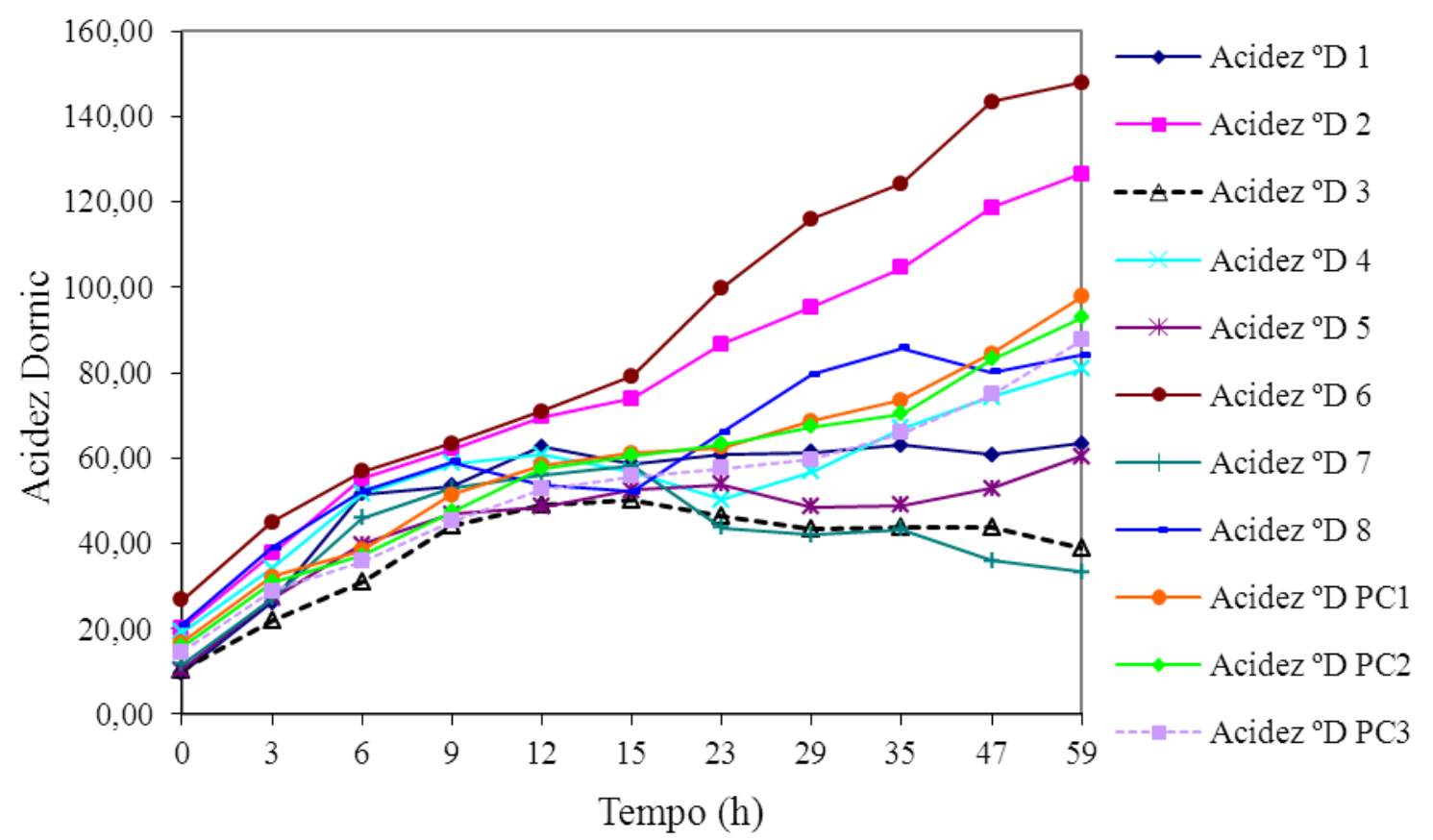

Figura 5 Comportamento da acidez ${ }^{\circ} \mathrm{D}$ do meio fermentativo alcoólico.

Verifica-se na Figura 5 que após a adição do inóculo aos ensaios, a acidez ${ }^{\circ} \mathrm{D}$ apresentou valores entre $10,06^{\circ} \mathrm{D}$ e 26,68 ${ }^{\circ} \mathrm{D}$, o que comprova que para o maior valor de $\mathrm{pH}$ medido $(6,00)$ há a correspondência da menor acidez ${ }^{\circ} \mathrm{D}$ encontrada (Ensaio VII); e para o menor $\mathrm{pH}$ medido $(4,56)$ verifica-se a maior acidez ${ }^{\circ} \mathrm{D}$ encontrada (Ensaio VI). Essa linha de raciocínio também é válida para os valores de acidez ${ }^{\circ} \mathrm{D}$ encontrados ao final da fermentação alcoólica, onde o 
Ensaio VI permaneceu apresentando a maior acidez $\left(147,84 \quad{ }^{\circ} \mathrm{D}\right) \quad \mathrm{e}$ consequentemente o menor $\mathrm{pH}$, enquanto o Ensaio VII mostrou-se o menos ácido dentre os onze ensaios $\left(33,24{ }^{\circ} \mathrm{D}\right)$, correspondendo também ao maior $\mathrm{pH}$ encontrado na Figura 4.

Pela Figura 5 é possível observar que os ensaios III e VII, desenvolveram um comportamento de acidez ${ }^{\circ} \mathrm{D}$ distintos dos demais fermentados alcoólicos ao longo do processo fermentativo. Tanto o Ensaio III, quanto o Ensaio VII apresentaram elevação da acidez ${ }^{\circ} \mathrm{D}$ nas primeiras $15 \mathrm{~h}$ de fermentação, seguida de redução dessa acidez com posterior estabilização. A análise conjunta da matriz do PEF (Tabela 2), percebe-se que ambos os ensaios (III e IV) foram submetidos às mesmas condições de temperatura $\left(28{ }^{\circ} \mathrm{C}\right)$ e agitação $(100 \mathrm{rpm})$. Essas evidências auxiliam no entendimento do comportamento da acidez ${ }^{\circ} \mathrm{D}$ dos dois ensaios. Sabe-se que durante a fermentação alcoólica há produção de gás carbônico $\left(\mathrm{CO}_{2}\right)$ e que a maior quantidade do gás é liberada durante a fermentação tumultuosa, que acontece nas primeiras horas da fermentação alcoólica (Barbosa et al, 2010; Diniz, 2009; Malta, 2006; Silveira, 2006).

$\mathrm{O} \mathrm{CO}_{2}$, quando dissolvido em água produz ácido carbônico $\left(\mathrm{H}_{2} \mathrm{CO}_{3}\right)$ aquoso, que devido a sua instabilidade, logo se decompõe em gás carbônico e água (Engarrafador Moderno, 2010; Vieira, 1996). Esta propriedade pode ter sido responsável pela redução da acidez ${ }^{\circ} \mathrm{D}$ após as primeiras $15 \mathrm{~h}$ de fermentação alcoólica, visto que, a princípio houve um elevado consumo de AR (Figura 3) e consequente produção de etanol e $\mathrm{CO}_{2}$. Devido a presença de agitação do meio fermentescível $(100 \mathrm{rpm}), \quad \mathrm{o} \quad \mathrm{CO}_{2}$ produzido foi homogeneizado $\mathrm{e}$ parcialmente solubilizado, formando ácido carbônico e provocando uma acidez ${ }^{\circ} \mathrm{D}$ "aparente", eliminada posteriormente devido a dissociação do $\mathrm{H}_{2} \mathrm{CO}_{3}$ em $\mathrm{CO}_{2} \mathrm{e}$ $\mathrm{H}_{2} \mathrm{O}$.

A redução da acidez se deu a partir de $15 \mathrm{~h}$ de fermentação, possivelmente devido ao decréscimo da atividade ENGEVISTA, V. 16, n. 3, p.392-409, Setembro 2014

fermentativa, o que resultou em uma menor produção de $\mathrm{CO}_{2}$ e consequente redução na formação de $\mathrm{H}_{2} \mathrm{CO}_{3}$. Percebeuse também que os ensaios III e VII apresentaram os menores valores de acidez ${ }^{\circ} \mathrm{D}$ finais. Tendo em vista que após a dissociação do $\mathrm{H}_{2} \mathrm{CO}_{3}$ e volatilização do $\mathrm{CO}_{2}$ a quantidade de substâncias com características ácidas presentes no meio foi mínima e a formação de produtos secundários foi baixa devido ao emprego da menor temperatura $\left(28^{\circ} \mathrm{C}\right)$.

Os ensaios I e $\mathrm{V}$ também foram submetidos à temperatura de $28^{\circ} \mathrm{C}$, porém não sofreram agitação, o que pode ter provocado um estresse celular à $S$. cerevisiae, resultando em mudança de rota metabólica, como cita Souza (2009), aumentando a concentração de produtos secundários no meio, que ocasionaram uma acidez ${ }^{\circ} \mathrm{D}$ final superior aos ensaios III e VII. Na Figura 5 ainda é possível observar que os ensaios (I, III, V e VII) submetidos à menor temperatura durante a fermentação apresentaram acidez ${ }^{\circ} \mathrm{D}$ menor que os demais ensaios, realizados em temperaturas de 32 e $36^{\circ} \mathrm{C}$.

Comparando os gráficos de comportamento do $\mathrm{pH}$ e da acidez ${ }^{\circ} \mathrm{D}$, evidencia-se que, conforme reduziu o $\mathrm{pH}$ do mosto, houve aumento da acidez do mesmo. Esta característica era esperada, tendo em vista que, para que ocorra a redução do $\mathrm{pH}$ compostos ácidos devem ser produzidos ou adicionados ao meio.

\subsection{CARACTERIZAÇÃO DO FERMENTADO ALCOÓLICO}

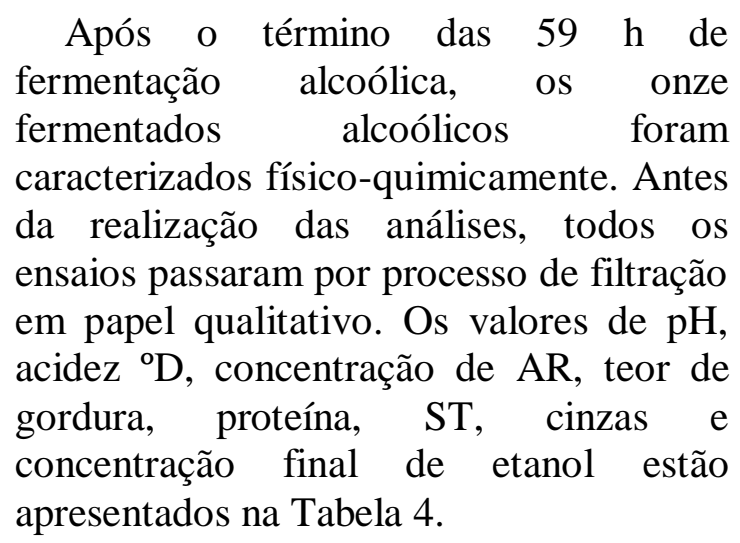


Se compararmos os valores finais obtidos de $\mathrm{pH}$ e acidez ${ }^{\circ} \mathrm{D}$ dos fermentados alcoólicos (Figura 4 e 5 tempo de $59 \mathrm{~h}$ ) com os apresentados na Tabela 4, resultados obtidos após armazenamento hermético em garrafa âmbar, proporcionando deste modo fermentação complementar na garrafa, é possível constatar que houve redução nos valores de $\mathrm{pH}$ e consequente aumento na acidez ${ }^{\circ} \mathrm{D}$ dos mesmos.

Com 59 h de fermentação, a acidez ${ }^{\circ} \mathrm{D}$, quantificada nos onze ensaios, apresentava valores entre 33,24 e 147,84 ${ }^{\circ} \mathrm{D}$. Após o envase e fermentação complementar na garrafa, esses valores ficaram entre 80,92 e $149,09^{\circ} \mathrm{D}$ conforme Tabela 4.

Tanto a redução do $\mathrm{pH}$, quanto a elevação da acidez ${ }^{\circ} \mathrm{D}$ do fermentado alcoólico após sofrer os processos de envase e fermentação complementar, podem ser explicados devido a produção de produtos secundários como ácidos orgânicos pela levedura $S$. cerevisiae que permaneceu fermentando o soro de leite após o envase. A fermentação complementar foi realizada para eliminar possíveis AR que permaneceram em suspensão após o término da fermentação alcoólica.

A concentração de gordura não foi analisada, considerando-se que o valor da mesma era inferior a $0,1 \%$, como informado na etapa de caracterização Tabela 3.

O teor de proteína obtido no produto fermentado alcoólico não apresentou grande variação quando comparado ao teor de proteína inicialmente presente no soro de leite $(0,83 \%)$. Os ensaios IV e VII permaneceram com o mesmo percentual proteico. Os demais ensaios apresentaram concentrações de proteínas inferiores à existente na matéria prima utilizada. Essa redução pode ter sido resultado do consumo do nitrogênio proteico como fonte de nutriente para a levedura conforme citado por Pinheiro (2004) em seus estudos, ou também devido à retenção de partículas sólidas no papel filtro qualitativo durante a filtração do fermentado alcoólico.

Tabela 4 Caracterização dos fermentados alcoólicos

\begin{tabular}{cccccccccc}
\hline Ensaio & $\mathbf{p H}$ & $\begin{array}{c}\text { Acidez } \\
\mathbf{}_{\mathbf{D}}\end{array}$ & $\begin{array}{c}\text { AR } \\
\mathbf{\%}\end{array}$ & $\begin{array}{c}\text { Proteína } \\
\mathbf{\%}\end{array}$ & $\begin{array}{c}\text { ST } \\
\mathbf{\%}\end{array}$ & $\begin{array}{c}\text { Cinzas } \\
\mathbf{\%}\end{array}$ & $\begin{array}{c}\text { DBO } \\
(\mathbf{m g . L}\end{array}$
\end{tabular}

Os sólidos totais presentes no produto fermentado apresentaram redução de até $29,21 \%$ (Ensaio III), comparado à composição inicial do soro de leite. Essa redução é devido ao consumo da lactose, 
bem como da separação de alguns sólidos durante a filtração.

O resíduo de incineração (cinzas), que corresponde ao teor de minerais presentes nos fermentados também se apresentou inferior ao encontrado inicialmente no soro de leite. O menor percentual de cinzas obtido no fermentado alcoólico foi de 0,44\% (Ensaio V), ou seja, 20\% a menos que o valor existente no soro de leite desnatado utilizado $(0,55 \%)$. Segundo Baldasso (2008); Pinheiro (2004) e Domingues (2001) alguns minerais, como o sódio, o zinco e o ferro podem ser utilizados pela levedura $S$. cerevisiae como fonte de micronutriente, ou também podem ter sido retidos durante a filtração dos fermentados.

As concentrações de etanol produzidos pela levedura $S$. cerevisiae também são apresentados na Tabela 4. Observa-se que a menor concentração de etanol produzida foi de 4,01\%, encontrada no Ensaio VI. Este ensaio, não sofreu agitação, foi submetido à maior temperatura $\left(36^{\circ} \mathrm{C}\right)$, recebeu a maior concentração da enzima lactase, porém recebeu adição da menor concentração de glicose $\left(45,0\right.$ g.L $\left.\mathrm{L}^{-1}\right)$. O baixo percentual de etanol encontrado no Ensaio VI deve-se principalmente à limitação de glicose no meio.

O Ensaio III apresentou o maior percentual de etanol produzido durante o processo fermentativo alcoólico $(6,41 \%)$. As condições estabelecidas pelo PEF, e aplicadas a este ensaio foram: menor temperatura $\left(28{ }^{\circ} \mathrm{C}\right)$, máxima agitação (100 rpm), menor adição de lactase $(0,05 \%)$ e máxima adição de glicose $(65,0$ g. $\left.\mathrm{L}^{-1}\right)$. Possivelmente, o emprego de temperatura reduzida, combinada com a adição de maior concentração de glicose fez com que o percentual de etanol produzido no Ensaio III fosse um dos maiores obtidos nesta pesquisa.

Utilizando como exemplo o Ensaio III, que produziu $6,41 \%$ de etanol, sendo que a concentração inicial de AR era de aproximadamente $12,8 \%$, calcula-se que para a obtenção de um grama de etanol foram necessários 2,0 g de AR.
Massud, Vallet e Martin (1999) obtiveram uma concentração de $2,5 \%$ de etanol após fermentação com Kluyveromyces fragilis, do soro de leite contendo 50,0 g.L $\mathrm{L}^{-1}$ de lactose, o que caracteriza o consumo de $2,0 \mathrm{~g}$ de lactose para produzir $1,0 \mathrm{~g}$ de etanol, assim como o encontrado na presente pesquisa.

A Demanda Química e Bioquímica de Oxigênio (DQO e DBO), encontrada nos fermentados alcoólicos produzidos apresentou redução de até $73,8 \%$ para a DBO e de até $75 \%$ para a DQO (Tabela 4), quando comparadas com o soro de leite desnatado in natura utilizado na produção desses fermentados.

Tanto a redução da $\mathrm{DBO}$, quanto a da DQO apontam para um decréscimo na quantidade de carga orgânica inicialmente encontrada no soro de leite. Esse decréscimo também pode ser identificado pela redução na quantidade de sólidos totais inicialmente presentes no soro, $6,06 \%$ para no máximo $2,16 \%$ nos fermentados alcoólicos produzidos. Essa redução é consequência principalmente do consumo e transformação da lactose a etanol, pela levedura $S$. cerevisiae.

Desta maneira, a fermentação alcoólica do soro de leite além de ser utilizada para a elaboração de bioetanol pode ser uma alternativa para a redução da carga orgânica presente neste resíduo agroindustrial. A redução da DBO e DQO minimiza o impacto ambiental que o mesmo pode ocasionar se não for tratado adequadamente nas estações de tratamento de efluentes industriais.

\section{4 EXPERIMENTAL \\ PLANEJAMENTO}

A produção de etanol foi avaliada estatisticamente, como sendo a única resposta de interesse na produção de fermentado alcoólico de soro de leite. Os efeitos principais das variáveis analisadas são apresentados na Tabela 5.

Das variáveis avaliadas (temperatura, agitação, concentração de enzima e 
concentração de glicose), somente a concentração de glicose (fonte de carbono) apresentou diferença significativa, para o intervalo de confiança de $90 \%$, sobre a produção de etanol.

Dragone et al (2009) estudou a influência da temperatura, concentração de lactose e concentração de inóculo na produção de etanol a partir de soro de leite, utilizando a Kluyveromyces fragilis, e obteve como resposta significativa para a concentração final de etanol, unicamente a concentração inicial de lactose, utilizada como fonte de carbono.

Tabela 5 Tabela de efeitos para a resposta $\%$ de etanol

\begin{tabular}{cccccc}
\hline Variação & Efeito & Erro Padrão & p-valor & Coeficiente & Erro Padrão \\
\hline Intercepto & 5,01 & 0,171 & 0,000 & 5,007 & 0,171 \\
\hline Temperatura & $-0,41$ & 0,400 & 0,345 & $-0,205$ & 0,200 \\
\hline Agitação & 0,46 & 0,400 & 0,294 & 0,230 & 0,200 \\
\hline Conc. Enzima & $-0,61$ & 0,400 & 0,178 & $-0,305$ & 0,200 \\
\hline Conc. Glicose* & $0,92^{*}$ & $0,400^{*}$ & $0,061^{*}$ & $0,460^{*}$ & $0,200^{*}$ \\
\hline
\end{tabular}

*Diferença significativa $(\alpha=0,10)$

A influência da concentração de glicose e das demais variáveis estudadas, pode ser melhor observada na Figura 6.

Por meio do Gráfico de Pareto e também pela Tabela de efeitos (Tabela 5) é possível constatar que a influência exercida pela concentração de glicose é significativa e positiva, ou seja, quanto maior a concentração de glicose adicionada ao soro de leite, maior será o percentual de etanol produzido.

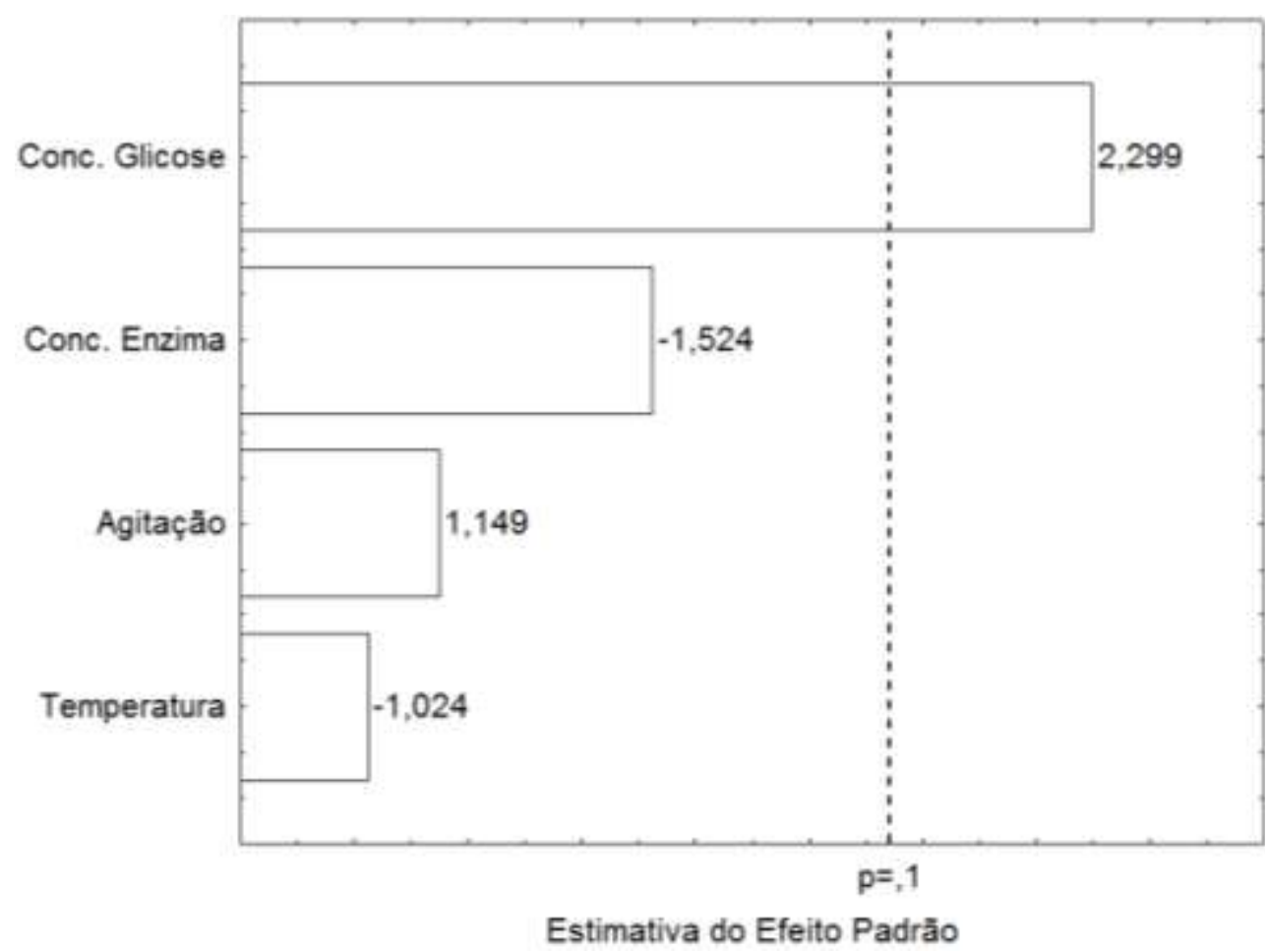

Figura 6 Gráfico de Pareto para a concentração de etanol. 
A agitação ou não dos meios fermentescíveis, durante a fermentação alcoólica, não exerceu influência significativa para a obtenção de etanol, porém seu efeito é positivo, podendo ocasionar aumento da concentração de etanol se for utilizada agitação durante o processo fermentativo.

A concentração de enzima lactase, adicionada ao soro de leite, bem como a variação de temperatura não apresentaram influência significativa, porém seu efeito sobre a concentração de etanol no fermentado alcoólico é negativo, ou seja, quanto maior a concentração de enzima lactase adicionada ao soro de leite e maior a temperatura utilizada durante o processo fermentativo, menor deverá ser a produção e consequente concentração de etanol.
Dessa forma, recomenda-se a utilização de uma menor concentração de enzima e também uma menor temperatura. Além de não prejudicar a produção de etanol, a redução na adição de enzima lactase reflete na diminuição dos custos de produção, tendo em vista que esta apresenta elevado valor comercial.

A Figura 7 apresenta a superfície de resposta para a concentração de etanol, em função da temperatura e da concentração de glicose adicionada. É possível observar claramente, que o aumento da concentração de glicose associada à redução da temperatura utilizada no processo acarretará maior produção e consequente concentração de etanol no fermentado alcoólico elaborado.

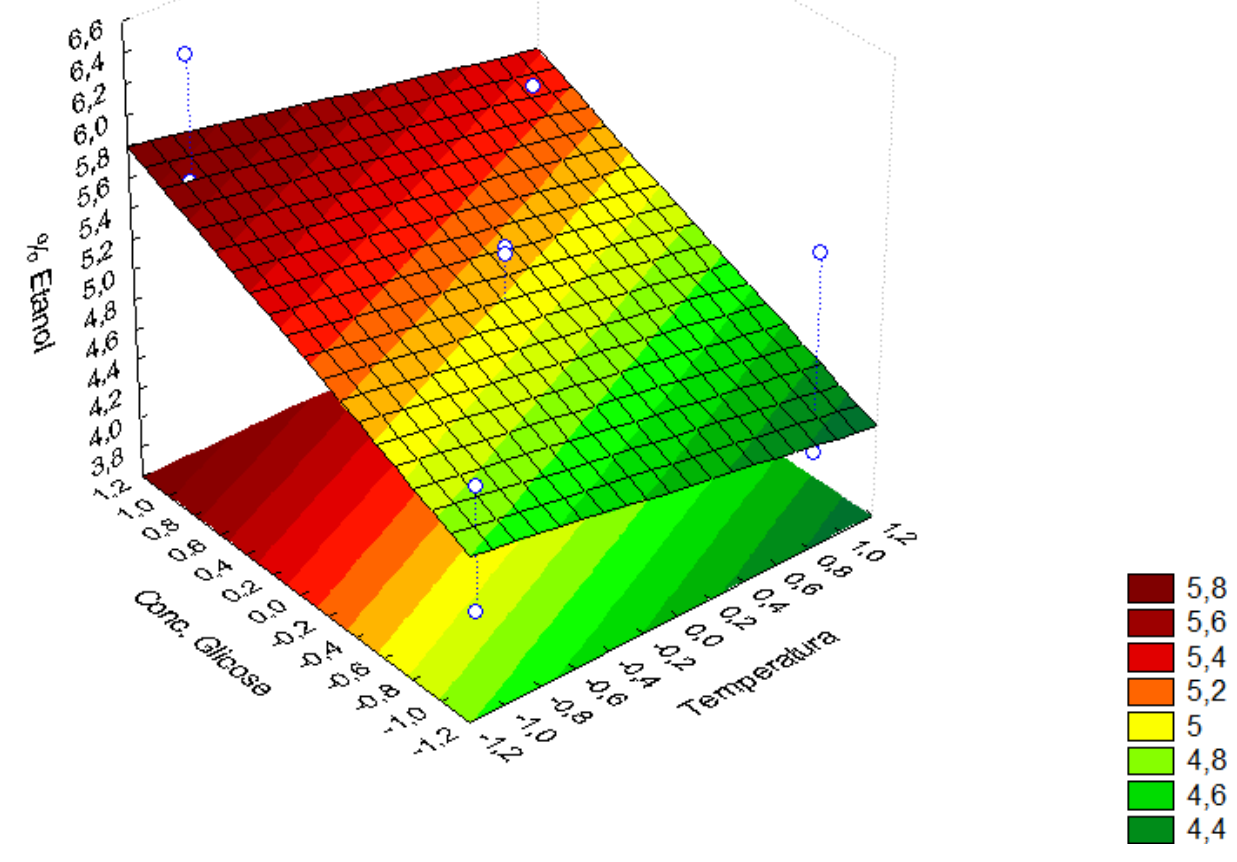

Figura 7 Superfície de resposta: concentração de etanol em função da temperatura e da concentração de glicose adicionada.

Sabendo que somente a concentração de glicose apresentou influência significativa e positiva sobre a produção de etanol, e que as demais variáveis não foram significativas no processo, para os intervalos estudados, subentendeu-se que 
as fermentações alcoólicas já estavam sendo executadas dentro das condições ótimas para a produção de etanol.

Para confirmar a produção de etanol proveniente da lactose do soro de leite, três fermentações controle foram realizadas durante 59 horas, a $28^{\circ} \mathrm{C}$ e sem agitação do meio fermentescível, conforme item 2.4.1: A (soro de leite in natura), B (soro de leite in natura acrescido de 65 g. $\mathrm{L}^{-1}$ de glicose) e C ( solução aquosa de glicose a 65 g.L $\mathrm{L}^{-1}$ ). Os resultados obtidos com estes experimentos são apresentados na Tabela 6.

Tabela 6 Caracterização dos fermentados alcoólicos-controle

\begin{tabular}{cccccccc}
\hline Ensaio & $\begin{array}{c}\text { Acidez } \\
{ }^{\mathbf{0}} \mathbf{D}\end{array}$ & $\mathbf{p H}$ & $\mathbf{A R} \%$ & $\begin{array}{c}\text { Proteínas } \\
\mathbf{\%}\end{array}$ & $\mathbf{S T} \%$ & $\begin{array}{c}\text { Cinzas } \\
\mathbf{\%}\end{array}$ & $\begin{array}{c}\text { Etanol } \\
\mathbf{\%}\end{array}$ \\
\hline $\mathbf{A}$ & 78,82 & 3,97 & $<0,6$ & 0,69 & 1,68 & 0,48 & 2,09 \\
$($ Soro $)$ & & & & & & & \\
\hline $\mathbf{B}$ & 88,40 & 3,06 & $<0,6$ & 0,73 & 1,75 & 0,49 & 5,20 \\
$($ Soro + Glicose) & & & & & & & \\
\hline $\mathbf{C}$ & 82,08 & 3,61 & $<0,6$ & 0,07 & 0,18 & 0,01 & 2,55 \\
(Água + Glicose) & & & & & & & \\
\hline
\end{tabular}

Conforme a Tabela 6, os valores de $\mathrm{pH}$ e acidez ${ }^{\circ} \mathrm{D}$, obtidos nos ensaios $\mathrm{A}, \mathrm{B}$ e $\mathrm{C}$, apresentam-se compatíveis com os valores observados na Tabela 4. O teor de proteína, sólidos totais (ST) e cinzas, para os ensaios A e B, também se equiparam aos apresentados na Tabela 4. O ensaio C apresentou baixos teores desses constituintes, pois o mesmo foi elaborado a partir de uma solução aquosa de glicose, não possuindo em sua constituição, nitrogênio orgânico e material mineral. Possivelmente os teores de proteína $(0,07 \%)$, ST $(0,18 \%)$ e cinzas $(0,01 \%)$, encontrados no fermentado alcoólico C são devidos à adição da levedura liofilizada.

O teor final de açúcares redutores (AR) em todos os ensaios realizados apresentou-se inferior a $0,6 \%$, sugerindo que os mesmos tenham sido utilizados pela levedura $S$. cerevisiae para a manutenção e multiplicação celular e também para a conversão em etanol.

Como esperado, os três ensaios controle produziram etanol, porém em concentrações distintas, conforme Tabela 6. A fermentação alcoólica controle "A", apresentou 2,09\% de etanol, ao final de 59 horas de fermentação. Este resultado demostra que a ação da enzima lactase foi efetiva na hidrólise da lactose em glicose e galactose, e conversão destas à etanol pela levedura $S$. cerevisiae. O ensaio B, contendo soro de leite in natura acrescido de glicose, apresentou um teor alcoólico final de $5,20 \%$, valore este, superior ao obtido no ensaio $\mathrm{A}$, onde não houve adição de glicose. $\mathrm{O}$ ensaio $\mathrm{C}$ apresentou uma concentração final de etanol igual a $2,55 \%$.

$\mathrm{O}$ rendimento em etanol, dos ensaios $\mathrm{A}, \mathrm{B}$ e $\mathrm{C}$ foi igual, respectivamente, a $43,91 \%, 46,18 \%$ e $39,23 \%$. O ensaio C apresentou rendimento $(39,23 \%)$ abaixo dos percentuais considerados adequados (43 a 49\%) por Bringhenti, et al (2007). A baixa conversão da glicose em etanol, neste ensaio, pode ser explicada devido à limitação de substratos importantes, como o nitrogênio orgânico, para o crescimento adequado da levedura, conforme Farina $e t$ al (2008). Na fermentação-controle $\mathrm{B}$, a produção $(5,20 \%)$ e rendimento de etanol $(46,18 \%)$ foram superiores às obtidas nos ensaios A e C. Estes resultados devem-se ao maior teor inicial de carboidrato no mosto (lactose presente naturalmente no soro de leite e da glicose adicionada), e 
também da existência de substratos adequados para o crescimento $\mathrm{e}$ desenvolvimento da levedura $S$. cerevisiae, como fonte de carbono e nitrogênio orgânico, encontrados no soro de leite.

Para a produção de bioetanol de soro de leite, o mesmo pode ser empregado no estado in natura ou ainda ser previamente concentrado. A utilização do soro in natura forneceria um fermentado alcoólico com menor teor alcoólico, enquanto que o emprego de soro parcialmente concentrado elevaria o teor inicial de AR (lactose) e consequentemente o teor final de etanol no fermentado alcoólico.

A fermentação alcoólica do soro de leite in natura ainda deve ser considerada do ponto de vista ambiental, tendo em vista que o processo fermentativo proporciona um decréscimo da carga poluidora deste resíduo agroindustrial.

\section{CONCLUSÃO}

Neste trabalho, verificou-se que a produção de etanol a partir do soro de leite não foi potencializada nas condições de agitação de 50 e $100 \mathrm{rpm}$, intervalo de temperatura $\left(28\right.$ a $\left.36^{\circ} \mathrm{C}\right)$ e variação na concentração de enzima lactase $(0,05$ a $0,1 \%$ ) adicionada ao soro de leite, conforme resultado estatístico obtido.

A única variável que apresentou influência significativa e positiva, para um intervalo de confiança de $90 \%$, foi a concentração de glicose adicionada ao meio.

O fermentado alcoólico que apresentou a maior concentração de etanol foi o ensaio de número III, submetido à temperatura de $28^{\circ} \mathrm{C}$, com agitação de 100 rpm, acrescido de $0,05 \%$ de enzima lactase e de 65,0 g.L $\mathrm{L}^{-1}$ de glicose P.A. Aconcentração de etanol desse ensaio foi de $6,41 \%$.

Após a fermentação alcoólica do soro de leite in natura desnatado, os valores de ENGEVISTA, V. 16, n. 3, p.392-409, Setembro 2014
DBO e DQO foram reduzidos em até $73,8 \%$ para a $\mathrm{DBO}$ e $75 \%$ para a DQO, demonstrando que além da obtenção de bioetanol desse resíduo pode-se também reduzir a carga poluidora do mesmo.

\section{5. BIBLIOGRÁFICAS}

\section{REFERÊNCIAS}

ALVES, R. L. D. Projeto da Rede de Captação Logística do Soro de Queijo Produzido no Estado de Minas Gerais. Minas Gerais: Departamento de Engenharia Elétrica. Universidade Federal de Viçosa, 2005. 33 p. Trabalho de Conclusão de Curso.

ANDRADE, A. C. De. Estudo da Fermentação Simultânea à Hidrólise de Soro de Queijo, Utilizando Lactase e Saccharomyces cerevisiae. Minas Gerais: Universidade Federal de Uberlândia, 2005. 110 p. Dissertação (Mestrado).

BALDASSO, C. Concentração, Purificação e Fracionamento das Proteínas do Soro Lácteo através da Tecnologia de Separação por Membranas. Porto Alegre: Escola de Engenharia. Universidade Federal do Rio Grande do Sul, 2008. 179 p. Dissertação (Mestrado).

BARBOSA, A. dos S.; ARAÚJO, A. dos S.; FLORÊNCIO, I. N.; BEZZERRA, R. R. de A.; FLORENTINO, E. R. Estudo Cinético da Fermentação do Soro de Queijo de Coalho para Produção de Aguardente. Revista Verde de Agroecologia e Desenvolvimento Sustentável Grupo Verde de Agricultura Alternativa (GVAA). V.5, n. 3, p 237-254, jul./set., 2010.

BRASIL. Instituto Brasileiro de Geografia e Estatística - IBGE. Tabela 1 - Produção e vendas dos produtos e/ou serviços industriais, segundo as classes de atividades e a descrição dos produtos Brasil - 2010. Disponível em: <ftp://ftp.ibge.gov.br/Industrias Extrativa s_e_de_Transformacao/Pesquisa_Industri al Anual/Produto2010/Tabela1.pdf>. Acesso em 25 de julho de 2012. 
BRASIL. Instrução Normativa $\mathrm{N}^{\circ} 68$ de 12 de dezembro de 2006. Métodos analíticos oficiais físico-químicos para controle de leite e produtos lácteos. Ministério da Agricultura Pecuária e Abastecimento, DF.

BRINGHENTI, L.; CABELLO, C.; URBANO, L. H. Fermentação alcoólica de substrato amiláceo hidrolisado enriquecido com melaço de cana. Ciência e Agrotecnologia. Lavras. V. 31, N. 2, p. 429-432, 2007.

CHRISTENSEN, A. D.; KÀDÀR, Z.; OLESKOWICZ-POPIEL, P.; THOMSEN, M. H. Production of bioethanol from organic whey using Kluyveromyces marxianus. J Ind Microbiol Biotechnol, 2010.

CORAZZA, M. L.; RODRIGUES, D. G.; NOZAKI, J. Preparação e caracterização do vinho de laranja. Química Nova, V. 24, N. 4, 449-452 p, 2001.

CUNHA, T. M.; ILHA. E. C.; AMBONI, R. D. M. C.; BARRETO, P. L. M.; CASTRO, F. P.; PRUDÊNCIO, E. S. A influência do uso de soro de queijo e bactérias probióticas nas propriedades de bebidas lácteas fermentadas. Brazilian Journal of Food Technology. V. 12. N. 1. p 23-33. Jan.-Mar. 2009.

DINIZ, R. H. S. Metabolismo de Lactose em Kluyveromyces marxianus UFV-3 e Kluyveromyces lactis JA6. Viçosa: Programa de Pós-Graduação em Engenharia Agrícola, Universidade Federal de Viçosa, 2009. 62 p. Dissertação (Mestrado).

DOMINGUES, L. M. R. Estirpes floculantes de Saccharomyces cerevisiae geneticamente modificada para a utilização da lactose: construção e aplicação biotecnológica. Braga: Escola de Engenharia, Universidade do Minho, 2001. 345 p. Tese (Doutorado).

DRAGONE, G.; MUSSATTO, S. I.; VILANOVA, M.; OLIVEIRA, J. M.; TEIXEIRA, J. A.; e SILVA, J. B. A. Obtenção e caracterização de bebida destilada a partir da fermentação do soro de queijo. Brazilian Journal of Food Technology. p. 120-124, junho de 2009.
ENGARRAFAMENTO

Embalagens atraem MODERNO.

Disponível

consumidores.

http://www.engarrafadormoderno.com.br/ edicoes/Edi\%C3\%A7\% C3\%A3o196.pdf. Acesso em: 02/01/2012.

FARINA, C. S.; LEMO, V.; ZÚÑIGA, U. F. R.; NETO, V. B.; COURI, S. Avaliação de Diferentes Resíduos Agroindustriais como Substratos para a Produção de Celulases por Fermentação Semi-sólida. Boletim de Pesquisa e Desenvolvimento EMBRAPA. São Carlos: EMBRAPA, 2008.

FONSECA, V. De C. Da. Elaboração de molho para salada com soro de queijo minas frescal estabilizado por combinações ternárias de alginato de propileno glicol, goma xantana e carboximetilcelulose. Curitiba: Setor de Tecnologia, Universidade Federal do Paraná, 2008. 133 p. Dissertação (Mestrado).

FORNARI, R. C. G. Aproveitamento de soro de queijo para produção de goma xantana. Erechim: Departamento de Ciências Agrárias, Universidade Regional Integrada do Alto Uruguai, 2006. 98 p. Dissertação (Mestrado).

HASHIZUME, T. Tecnologia do Vinho. In: AQUARONE, E. et al. Biotecnologia Industrial. $1^{a}$ ed. V. 4. São Paulo: Edgard Blücher LTDA, 2001, 523 p. 21-68 p.

INSTITUTO ADOLFO LUTZ. Normas Analíticas do Instituto Adolfo Lutz Métodos físico-químicos para análise de alimentos. $4^{\mathrm{a}}$ ed. Brasília, DF: Ministério da Saúde, 2005. 1018 p.

KARGI, F.; OZMIHCI, S. Utilization of cheese whey powder (CWP) for ethanol fermentations: Effects of operating parameters. Science Direct. p. 711-718. 2005.

MASUD, Z.; VALLET, C.; MARTIN, G. J. Stable Isotope Characterization of Milk Components and Whey Ethanol. J. Agric. Food Chem. V. 47, p. 4693-4699, 1999.

MALTA, H. L. Estudos de parâmetros de propagação de fermento (Saccharomyces cerevisiae) para produção de cachaça de 
alambique. Belo Horizonte: Faculdade de Farmácia, Universidade Federal de Minas Gerais, 2006. 70 p. Dissertação (Mestrado).

PELEGRINE, D. H. G.; CARRASQUEIRA, R. L. Aproveitamento do soro do leite no enriquecimento nutricional de bebidas. Brazilian Journal of Food Technology. p. 145-151. Dez. 2008.

PINHEIRO, R. I. C. Estudo do Efeito da Pressão na Fisiologia de Leveduras. Portugal: Escola de Engenharia, Universidade do Minho, 2004. 292 p. Tese (Doutorado).

SILVEIRA, R. F. Produção de Etanol por Leveduras em Biorreatores com Células Livres e Imobilizadas Utilizando Soro de Queijo. Porto Alegre: Faculdade de Agronomia, Universidade Federal do Rio Grande do Sul, 2006. 131 p. Dissertação (Mestrado).

SOUZA, C. S. Avaliação da Produção de Etanol em Temperaturas Elevadas por uma Linhagem de $S$. cerevisiae. São Paulo: Programa de Pós-Graduação
Interunidades em Biotecnologia, USP/Instituto Butantan/IPT, 2009. 49 p. Tese (Doutorado).

STATSOFT, Inc. (2004). STATISTICA (data analysis software system), version 8.0.

SUZART, C. A. G., DIAS, J. C. T. Desenvolvimento tecnológico de aguardente de soro de queijo. Projeto Bolsa BITEC, IEL, SEBRAE e CNPQ. 2007.

TEIXEIRA, L. V.; FONSECA, L. M. Perfil físico-químico do soro de queijos mozarela e minas padrão produzidos em várias regiões do Estado de Minas Gerais. Arq. Bras. Med. Vet. Zootc. V. 60, n. 1. p. 243-250, 2008.

TORIJA, M. J.; ROZÈS, N.; POBLET, M.; GUILLAMÓN, J. M.; MAS, A. Effects of fermentation temperature on the strain population of Saccharomyces cerevisiae. International Journal of Food Microbiology. V. 80, p. 47-53, 2000.

VIEIRA, L. Química, Saúde \& Medicamentos. Porto Alegre, 1996. 52 p. Apostila. 